\title{
ANÁlISE CROMATOGRÁFICA DOS GASES PRODUZIDOS NA CO-PIRÓLISE DE PNEUS EM LEITO FLUIDIZADO COM SUPORTE DE AREIA DE FUNDIÇÃO
}

\author{
B. S. SCOPEL ${ }^{1}$, D. PERONDI ${ }^{2}$, G. COLLAZZO ${ }^{1}$, A. DETTMER ${ }^{1}$, M. GODINHO ${ }^{1}$, A.C.F. \\ VILELA $^{2}$ \\ ${ }^{1}$ Universidade de Caxias do Sul, Centro de Ciências Exatas e Tecnologia \\ 2 Programa de Pós-Graduação em Engenharia de Minas, Metalúrgica e de Materiais \\ E-mail para contato: bianca.scopel1@gmail.com
}

\begin{abstract}
RESUMO - A co-pirólise é uma vantajosa alternativa para a disposição de resíduos industriais visto que permite o aproveitamento dos produtos gerados. A utilização do gás pirolítico como fonte de energia depende diretamente de sua caracterização, uma vez que a composição determina o seu potencial como combustível. O objetivo deste trabalho consistiu no desenvolvimento e avaliação de metodologia para a análise qualitativa e quantitativa do gás proveniente da copirólise de pneus em leito fluidizado com suporte de areia de fundição. Os ensaios foram realizados a $500^{\circ} \mathrm{C}$ e amostras do gás foram analisadas por cromatografia gasosa (CG). Foram empregadas duas configurações de análise com uma coluna Porapak Q e dois detectores: condutividade térmica e ionização de chama. A análise qualitativa do gás pirolítico indicou a presença de $\mathrm{H}_{2}, \mathrm{CO}, \mathrm{CO}_{2}, \mathrm{O}_{2}, \mathrm{CH}_{4}$, $\mathrm{C}_{2} \mathrm{H}_{6}, \mathrm{C}_{2} \mathrm{H}_{4}$ e hidrocarbonetos com cadeias de 3 carbonos. Foram determinadas altas concentrações, em base molar, de $\mathrm{H}_{2}$ e $\mathrm{CH}_{4}, 47,69 \%$ e 33,09\%, respectivamente, e poder calorífico do gás igual a $53 \mathrm{MJ} / \mathrm{kg}$, indicando que este pode ser utilizado como combustível.
\end{abstract}

\section{INTRODUÇÃO}

A geração de rejeitos provenientes de fundição e o descarte de pneus usados configuram dois grandes desafios na gestão de resíduos sólidos. A indústria de fundição no Brasil, no período de 2004 a 2009, produziu de 2 a 3 milhões de toneladas de fundidos por ano. Cada tonelada de metal processado gera de 0,25 a 1,00 tonelada de resíduo sólido, 30 a $60 \%$ deste composto por areia de fundição (Klinsky, 2013). Parte desta areia possui em sua composição teores de fenol, conhecido por sua alta periculosidade (Siddique; Singh, 2011). Com relação ao descarte de pneus, a Associação Nacional da Indústria de Pneumáticos (ANIP) (2013) indica que no ano de 2012 foram vendidas e, consequentemente, descartadas, 67,9 milhões de unidades no Brasil.

A co-pirólise de pneus em leito fluidizado com suporte de areia de fundição surge como alternativa para a disposição dos referidos resíduos. Além de configurar um destino adequado aos resíduos, Perondi (2013) verificou a degradação do fenol durante o processo de copirólise devido às altas temperaturas empregadas, eliminando o caráter perigoso associado à areia de fundição. 
A pirólise é caracterizada pela decomposição térmica de matéria orgânica através da quebra de ligações químicas em condições não oxidantes: meio inerte ou vácuo (Klass, 1998; Rombaldo, 2008). A pirólise de pneus gera três frações de novos compostos: óleo, gás e char. Os referidos produtos podem ser aplicados como combustíveis ou matéria-prima na obtenção de outros compostos (Cunliffe; Williams, 1998; Martínez et al., 2013).

A utilização do gás da co-pirólise como fonte de energia depende diretamente da sua caracterização. A composição do gás determinará seu potencial como combustível e também indicará a possível necessidade de pré-tratamento deste para posterior utilização.

Rodriguéz et al. (2001) e Laresgoiti et al. (2000) afirmam que os gases de pirólise de pneus são principalmente compostos de hidrocarbonetos além de certas quantidades de $\mathrm{CO}$, $\mathrm{CO}_{2}$ e $\mathrm{H}_{2} \mathrm{~S}$. Cunliffe e Williams (1998) citam a formação de grandes quantidades de $\mathrm{C}_{4} \mathrm{H}_{6}$ além de $\mathrm{H}_{2}, \mathrm{CH}_{4}, \mathrm{CO}$ e $\mathrm{CO}_{2}$. De acordo com Rodriguéz et al. (2001) o PCS do gás de pirólise de pneus é de aproximadamente $40 \mathrm{MJ} / \mathrm{kg}$. Já Laresgoiti et al. (2000) encontraram valores que variavam de 69,5 a $81,6 \mathrm{MJ} / \mathrm{kg}$.

A cromatografia gasosa (CG) é amplamente empregada na análise de compostos orgânicos gasosos e de gases permanentes (Ciola, 1973). O resultado de uma corrida cromatográfica é indicado em um cromatograma. Ele registra a resposta de um detector em função do tempo de eluição (de passagem do gás pela coluna cromatográfica) (Harris, 2012).

O tempo de retenção $\left(t_{r}\right)$ indica o tempo gasto desde o ato de injeção da amostra até a saída do ponto máximo do pico do sistema. Em configurações analíticas semelhantes, uma substância apresenta um $t_{r}$ característico, usado para a análise qualitativa das amostras (Collins; Braga; Bonato, 2006).

A concentração de um composto pode ser determinada pela área sob a curva do seu pico em conjunto com o emprego de fatores de correção tabelados para o composto em questão. $\mathrm{O}$ fator de correção empregado ao usar TCD como detector é o de resposta térmica e, quando do uso do FID, é o de sensibilidade relativa (Ciola, 1973; Hage; Carr, 2012).

A avaliação de uma corrida cromatográfica pode ser realizada através do cálculo da resolução dos picos (avalia separação de picos entre compostos - valores ideais acima de 1,0) e do número de pratos da coluna empregada.

A resolução é a medida utilizada para avaliar a separação entre componentes adjacentes. Para análises quantitativas, valores de resolução considerados bons são aqueles superiores a 1,5 (separação completa dos picos); para as qualitativas, valores superiores a 1,0 já são adequados (McGuffin, 2004).

A eficiência de uma coluna é medida em termos de números de pratos. Um prato corresponde a uma etapa de equilíbrio da substância entre a fase estacionária e a fase móvel; portanto, quanto maior o número de pratos, maior será a eficiência (picos mais estreitos) (Collins; Braga; Bonato, 2006).

O objetivo deste trabalho consistiu no desenvolvimento e avaliação de uma metodologia para a caracterização, por meio de CG, dos gases provenientes da co-pirólise de pneus em leito fluidizado com suporte de areia de fundição. 


\section{MATERIAIS E MÉTODOS}

\subsection{Ensaios de co-pirólise e amostragem do gás}

Amostras provenientes de moagem mecânica de borracha vulcanizada e areia de fundição contaminada com fenol foram utilizadas nos experimentos, sendo a primeira degradada para formação de char, óleo e gás e, a segunda, utilizada como suporte do leito.

Seis ensaios de co-pirólise foram realizados em um reator de leito fluidizado na temperatura de $500^{\circ} \mathrm{C}$. O gás gerado foi separado do char e do óleo através de um sistema de condensação e uma amostra de cada ensaio foi coletada em um bag para amostragem de gases. O reator pirolítico e o sistema de amostragem do gás estão representados na Figura 1.

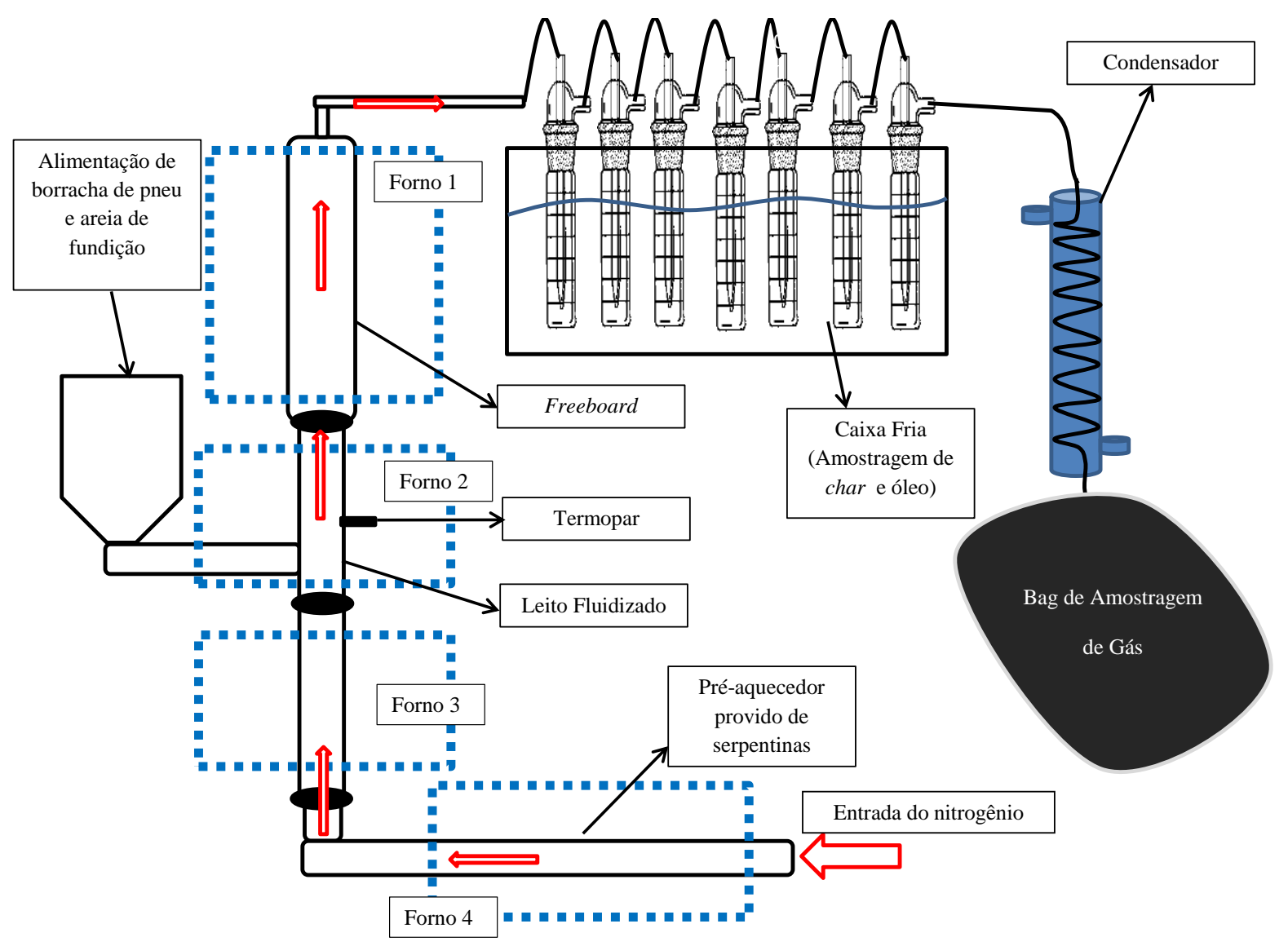

Figura 1 - Reator utilizado na co-pirólise e sistema de amostragem do gás.

\subsection{Análise cromatográfica dos gases de pirólise}

Para a análise qualitativa e quantitativa do gás pirolítico foi utilizado um cromatógrafo gasoso Auto System XL da marca Perkin Eimer provido de dois detectores: FID e TCD. Foi selecionada uma coluna empacotada Porapack Q de 3,6 m de comprimento para a separação dos componentes presentes na amostra. $\mathrm{O}$ gás de arraste utilizado foi o nitrogênio. No caso 
de utilização do FID, hidrogênio e ar foram empregados para alimentação da chama do detector. Duas configurações de análise foram utilizadas, conforme resumido na Tabela 1.

Tabela 1 - Configurações utilizadas em CG para análise de gás de pirólise

\begin{tabular}{|c|c|c|}
\hline & Configuração 1 & Configuração 2 \\
\hline Gases possíveis de serem determinados & $\begin{array}{c}\mathrm{H}_{2}, \mathrm{CO}+\mathrm{O}_{2}, \mathrm{CO}_{2}, \mathrm{CH}_{4}, \\
\mathrm{C} 2 \text { e C3 }\end{array}$ & $\mathrm{CH}_{4}, \mathrm{C} 2, \mathrm{C} 3, \mathrm{C} 4$ e $\mathrm{C} 5$ \\
\hline Coluna cromatográfica & Porapak Q & Porapak Q \\
\hline Detector & TCD & FID \\
\hline Gás de arraste & $\mathrm{N}_{2}$ & $\mathrm{~N}_{2}$ \\
\hline Vazão do gás de arraste (ml/min) & 30 & 30 \\
\hline Temperatura da coluna $\left({ }^{\circ} \mathrm{C}\right)$ & 60 & 140 \\
\hline Temperatura do injetor $\left({ }^{\circ} \mathrm{C}\right)$ & 100 & 100 \\
\hline Temperatura do detector $\left({ }^{\circ} \mathrm{C}\right)$ & 100 & 200 \\
\hline Tempo da corrida (min) & 8 & 16 \\
\hline Volume de amostra (ml) & 0,3 & 0,3 \\
\hline
\end{tabular}

A concentração dos gases presentes na amostra foi calculada a partir da área sob os picos dos compostos detectados e através da interposição dos resultados obtidos nas duas configurações em separado.

A resolução dos picos gerados na cromatografia foi calculada pelo dobro da razão entre a diferença dos tempos de retenção de dois compostos adjacentes e a soma da largura da base destes picos (McGuffin, 2004).

A eficiência da coluna cromatográfica foi calculada pela razão entre o quadrado do tempo de retenção de um pico pelo quadrado da largura da sua base, multiplicada por 16 (Collins; Braga; Bonato, 2006, p. 207).

Visto que nas duas as configurações foram determinados hidrocarbonetos de 2 (C2) e 3 (C3) carbonos, o número de mols obtidos em ambas foram comparados: quanto mais próximos os valores encontrados, maior a confiabilidade da análise.

Utilizando-se o TCD, a área sob a curva de cada composto detectado foi dividida pelo seu respectivo fator de resposta gerando a sua área corrigida. A normalização (divisão da área corrigida de um composto pelo somatório das áreas corrigidas de todos os compostos) resultou no percentual molar de um determinado componente.

Ao se empregar o FID, a área sob a curva de um composto foi dividida pela sensibilidade relativa gerando sua área corrigida. A normalização dos resultados resultou no percentual em massa de cada composto, por sua vez convertido para percentual molar (Dietz, 1967).

O PCS do gás pirolítico foi calculado através do somatório do produto da fração mássica de cada um de seus componentes (em base livre de nitrogênio) pelo respectivo PCS. 


\section{RESULTADOS}

A análise qualitativa do gás proveniente da co-pirólise indicou a existência dos seguintes componentes: hidrogênio, monóxido de carbono, dióxido de carbono, oxigênio, metano, etano, eteno e hidrocarbonetos com cadeias de 3 carbonos.

A Figura 2 apresenta dois dos cromatogramas obtidos, ambos referentes ao gás gerado em um dos seis ensaios realizados. Nas imagens já está inserida a informação do tempo de retenção de cada pico e também a qual composto este pertence.

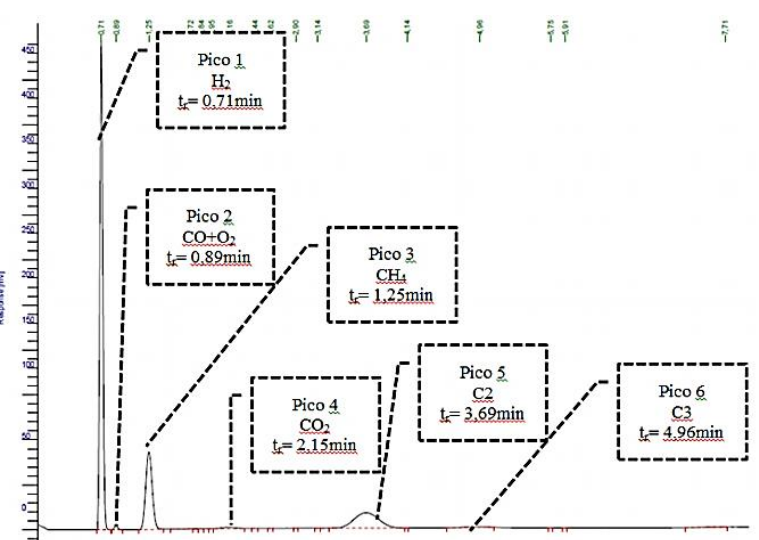

(a)

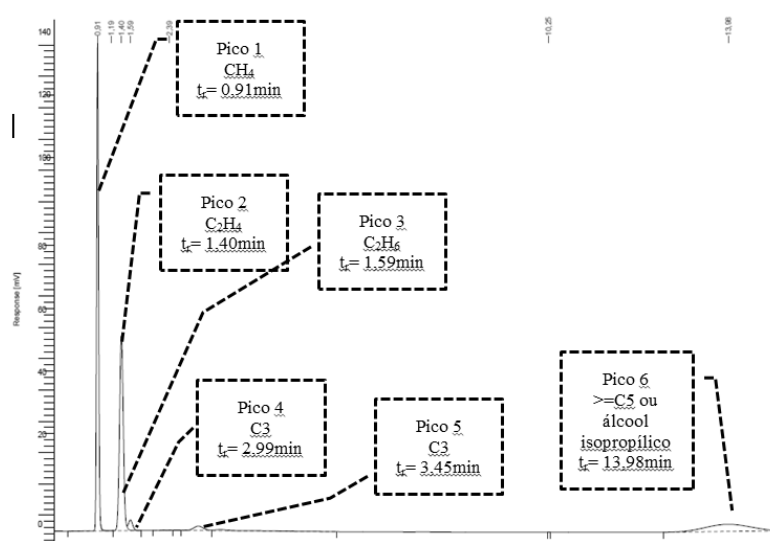

(b)

Figura 2 - (a) Cromatograma referente à configuração de análise 1. (b) Cromatograma referente à configuração de análise 2 .

O pico 6 apresentado na Figura 2 (b) representa os hidrocarbonetos de maior MM (com 5 ou mais carbonos na cadeia) ou álcool isopropílico utilizado no sistema de amostragem do gás. Isto indica provável contaminação do gás, seja pelo óleo de pirólise (hidrocarbonetos de 5 ou mais carbonos) que condensou no bag, seja pelo álcool utilizado na amostragem. Em virtude desta incerteza este pico foi desconsiderado.

Observa-se que, com a configuração analítica utilizada, os picos de oxigênio e monóxido de carbono se sobrepõem, resultando em valores de concentração dos dois compostos somados.

Valores consideráveis de hidrogênio (47,69 \% em base molar) foram encontrados, assim como de metano $(33,09 \%$ em base molar) e hidrocarbonetos com dois carbonos na cadeia $(12,37 \%$ em base molar) que, juntos, perfazem mais de $90 \%$ em base molar do gás. A Tabela 2 apresenta os resultados detalhados. 
Tabela 2 - Concentração molar dos compostos presentes na amostra de gás pirolítico

\begin{tabular}{|c|c|c|c|c|c|c|c|}
\hline Ensaio & \multicolumn{7}{|c|}{ Concentração (\% molar) } \\
\hline & $\mathrm{H}_{2}$ & $\mathrm{CO}+\mathrm{O}_{2}$ & $\mathrm{CH}_{4}$ & $\mathrm{CO}_{2}$ & $\mathrm{C}_{2} \mathrm{H}_{4}$ & $\mathrm{C}_{2} \mathrm{H}_{6}$ & $\mathrm{C} 3$ \\
\hline 1 & 38,02 & 8,74 & 36,72 & N.D. & 15,52 & 0,62 & 0,37 \\
\hline 2 & 71,42 & 11,53 & 16,26 & N.D. & 0,52 & 0,24 & 0,02 \\
\hline 3 & 39,49 & 6,28 & 32,26 & 0,61 & 19,74 & 0,46 & 1,15 \\
\hline 4 & 54,47 & 3,14 & 35,22 & 0,77 & 5,88 & 0,49 & 0,03 \\
\hline 5 & 43,62 & 4,22 & 37,82 & 0,42 & 13,02 & 0,59 & 0,30 \\
\hline 6 & 39,14 & 0,96 & 40,23 & 1,00 & 16,71 & 0,92 & 1,04 \\
\hline Média & 47,69 & 5,81 & 33,09 & 0,47 & 11,90 & 0,55 & 0,49 \\
\hline Desvio Padrão & 13,66 & 4,01 & 9,47 & 0,25 & 7,89 & 0,25 & 0,55 \\
\hline
\end{tabular}

Díez (2004) e Aylón (2007) também encontraram altos percentuais molares de hidrogênio (de 24 a $40 \%$ ) e metano (de 20 a $26 \%$ ) no gás de pirólise de pneus. Díetz (2004) obteve de 20 a $29 \%$ de hidrocarbonetos C2 e Aylón (2007), por sua vez, obteve aproximadamente $11 \%$, valor muito semelhante ao apresentado pelas amostras neste trabalho analisadas. Evidencia-se desta forma que o uso da areia de fundição como suporte do leito fluidizado não influi consideravelmente na composição do gás pirolítico.

Observa-se que, de maneira geral, um aumento na concentração de hidrogênio representa uma diminuição na concentração dos hidrocarbonetos e vice-versa.

A análise da Figura 3 permite afirmar que as duas diferentes configurações empregadas apresentaram resultados muito próximos em termos de número de mols de $\mathrm{C} 2$ e $\mathrm{C} 3$, com apenas uma discrepância para mols de C3 na amostra de número 3. Pode-se, portanto, atestar a confiabilidade do método analítico empregado.

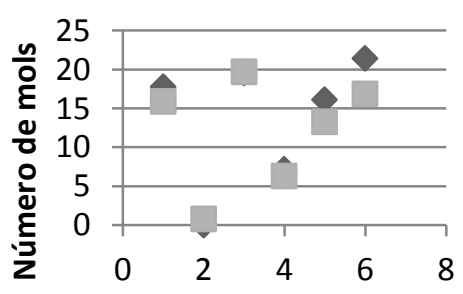

(a)

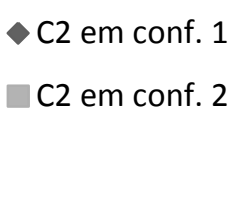

Ensaio

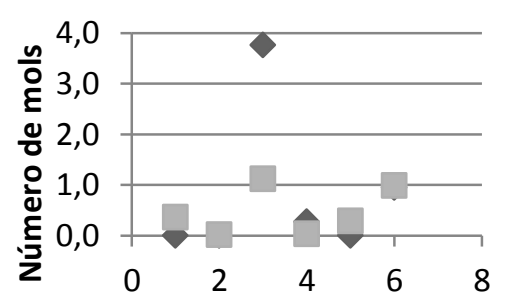

(b) $\diamond \mathrm{C} 3$ em conf. 1

C3 em conf. 2

Figura 3 - (a) Comparação entre número de mols de $\mathrm{C} 2$ encontrados nas configurações de análise 1 e 2 (b) Comparação entre número de mols de C3 encontrados nas configurações de análise 1 e 2.

$\mathrm{Na}$ avaliação da metodologia escolhida, aproximadamente $75 \%$ dos picos apresentaram valores de resolução acima de 1,0, adequados para análise qualitativa. A eficiência média da coluna empregada foi de 176 pratos por metro.

O PCS calculado para o gás de pirólise gerado variou de 49,95 MJ/kg até 57,88 MJ/kg (variando de amostra para amostra gerada), sendo a média dos valores igual a 53,00 MJ/kg. 
Ao comparar os valores obtidos com o PCS do gás natural (52 MJ/kg), percebe-se que este gás pode ser utilizado como combustível. Indica-se, entretanto, a realização de mais ensaios para verificar a existência de contaminantes prejudiciais ao processo de combustão. Também deve-se avaliar possíveis pré-tratamentos necessários para o gás em questão.

\section{CONCLUSÕES}

O desenvolvimento deste trabalho possibilitou verificar que as configurações de análise 1 (coluna: Porapak Q, gás de arraste: $\mathrm{N}_{2}$, detector: TCD) e 2 (coluna: Porapak Q, gás de arraste: $\mathrm{N}_{2}$, detector: FID) apresentaram resultados satisfatórios tanto na análise qualitativa como na quantitativa dos gases por cromatografia gasosa. Bons resultados foram obtidos para a maioria dos picos em termos de separação (valores de resolução acima de 1,0). Ainda assim, notou-se a necessidade de aplicação de uma segunda coluna para a separação do pico de monóxido de carbono e oxigênio bem como o ajuste da vazão do gás de arraste e da temperatura da coluna a fim de diminuir a largura da base dos picos (e aumentar o número de pratos por metro da coluna empregada);

A análise quantitativa do gás mostrou concentrações relevantes de hidrogênio $(47,69 \%$ $\mathrm{mol} / \mathrm{mol})$, metano $(33,09 \% \mathrm{~mol} / \mathrm{mol})$ e eteno $(11,90 \% \mathrm{~mol} / \mathrm{mol})$. Os referidos valores se aproximam daqueles já apresentados por alguns autores para a análise de gás proveniente de pirólise de pneus a temperaturas próximas $\operatorname{dos} 500^{\circ} \mathrm{C}$, utilizada nos ensaios deste trabalho;

A composição do gás além do alto valor de PCS para este obtido, igual a $53 \mathrm{MJ} / \mathrm{kg}$, permitem inferir que o mesmo pode ser utilizado em sistemas de combustão. A condução de novos ensaios para a determinação da existência ou não de contaminantes não detectados nas análises efetuadas neste trabalho, e que possam ser prejudiciais ao processo de combustão, são ainda necessárias.

\section{REFERÊNCIAS BIBLIOGRÁFICAS}

ASSOCIAÇÃO NACIONAL DA INDÚSTRIA DE PNEUMÁTICOS. Produção da Indústria Brasileira de Pneus em 2012, 2013.

AYLÓN, E. et al. Emissions from the combustion of gas-phase products at tyre pyrolysis. $J$. Anal. Appl. Pyrol., n.79, p. 210-214, 2007.

CIOLA, R. Introdução à cromatografia em fase gasosa. São Paulo: E. Blücher, 1973. 231 p.

COLLINS, C. H.; BRAGA, G. L.; BONATO, P. S. Fundamentos de cromatografia. Campinas: UNICAMP, 2006. 453 p.

CUNLIFFE, A. M.; WILLIAMS, P. T. Composition of oils derived from the batch pyrolysis of tyres. J. Anal. Appl. Pyrol, n. 44, p. 131-152, 1998.

DÍEZ, C. et al. Pyrolysis of tyres: influence of the final temperature of the process on emissions and the calorific value of the products recovered. Waste Manag., n. 24, p. 463-469, 2004. 
DIETZ, W. A. Response Factors for Gas Chromatographic Analyses. J. Gas Chromatogr., Oxford, n.5, p. 68-71,1967.

HAGE, D. S.; CARR, J. D. Química analítica e análise quantitativa. São Paulo: Pearson, 2012. $708 \mathrm{p}$.

HARRIS, D. C. Análise Química Quantitativa. Rio de Janeiro: LTC, 2012. 898 p.

KLASS, D. L. Thermal Conversion: Pyrolysis and Liquefation. In: . Biomass Ren. Energ., Fuels, and Chem.. San Diego: Academic Press, 1998. p. 225-269.

KLINSKY, L. M. G. Avaliação do reaproveitamento de areia de fundição residual em camadas de pavimento. 2013, 279. Tese (Doutorado em Engenharia de Transporte) Escola de Engenharia de São Carlos, Universidade de São Paulo, São Paulo, 2013..

LARESGOITI, M. F.; MARCO, I; TORRES, A.; CABALLERO, B.; CABRERO, M.; CHOMÓN, M. J. Chromatographic analysis of the gases obtained in tyre pyrolysis. $J$. Anal. Appl. Pyrol., n. 55, p. 43 - 54, 2000.

MARTÍNEZ, J. D.; PUY, N.; MURILLO, R.; GARCÍA, T.; NAVARRO, M. V.; MASTRAL A. M. Waste tyre pyrolysis - A review. Renew. Sust. Energ. Rev., n. 23, p. 179-213, 2013.

PERONDI, D. Copirólise de pneus e resina polimérica presente na areia de fundição em um reator de leito fluidizado. 2013. 84 f. Dissertação (Mestrado em Engenharia de Processos e Tecnologias) - Programa de Pós Graduação em Engenharia de Processos e Tecnologias, Universidade de Caxias do Sul, Caxias do Sul, 2013.

RODRIGUÉZ, I. M.; LARESGOITI, M. F.; CABRERO, M. A.; TORRES, A.; CHOMÓN, M. J.; CABALLERO, B. Pyrolisis of scrap tyres. Fuel Process. Technol., n. 72, p. $9-$ 22, 2001.

ROMBALDO, C. F. S. Síntese de Carvão Ativado e Óleo Combustível a Partir da Borracha de Pneu Usado. 2008. 108 f. Dissertação (Mestrado em Engenharia Química) Programa de Pós-Graduação em Engenharia Química, Universidade Estadual de Campinas, Campinas, 2008.

SIDDIQUE, R.; SINGH, G. Utilization of waste foundry sand (WFS) in concrete manufacturing. Resour. Conserv. Recy., n. 55, p. 885 - 892, 2011. 